\title{
Retrieval of ozone profiles from OMPS limb scattering observations
}

\author{
Carlo Arosio $^{1}$, Alexei Rozanov ${ }^{1}$, Elizaveta Malinina ${ }^{1}$, Kai-Uwe Eichmann ${ }^{1}$, Thomas von Clarmann ${ }^{2}$, and \\ John P. Burrows ${ }^{1}$ \\ ${ }^{1}$ Institute of Environmental Physics, University of Bremen, Bremen, Germany \\ ${ }^{2}$ Karlsruhe Institute of Technology, Karlsruhe, Germany
}

Correspondence: Carlo Arosio (carloarosio@iup.physik.uni-bremen.de)

Received: 15 August 2017 - Discussion started: 22 August 2017

Revised: 28 February 2018 - Accepted: 14 March 2018 - Published: 13 April 2018

\begin{abstract}
This study describes a retrieval algorithm developed at the University of Bremen to obtain vertical profiles of ozone from limb observations performed by the Ozone Mapper and Profiler Suite (OMPS). This algorithm is based on the technique originally developed for use with data from the SCanning Imaging Absorption spectroMeter for Atmospheric CHartographY (SCIAMACHY) instrument. As both instruments make limb measurements of the scattered solar radiation in the ultraviolet (UV) and visible (Vis) spectral ranges, an underlying objective of the study is to obtain consolidated and consistent ozone profiles from the two satellites and to produce a combined data set. The retrieval algorithm uses radiances in the UV and Vis wavelength ranges normalized to the radiance at an upper tangent height to obtain ozone concentrations in the altitude range of $12-60 \mathrm{~km}$. Measurements at altitudes contaminated by clouds in the instrument field of view are identified and filtered out. An independent aerosol retrieval is performed beforehand and its results are used to account for the stratospheric aerosol load in the ozone inversion. The typical vertical resolution of the retrieved profiles varies from $\sim 2.5 \mathrm{~km}$ at lower altitudes $(<30 \mathrm{~km})$ to $\sim 1.5 \mathrm{~km}$ (about $45 \mathrm{~km}$ ) and becomes coarser at upper altitudes. The retrieval errors resulting from the measurement noise are estimated to be $1-4 \%$ above $25 \mathrm{~km}$, increasing to $10-30 \%$ in the upper troposphere. OMPS data are processed for the whole of 2016. The results are compared with the NASA product and validated against profiles derived from passive satellite observations or measured in situ by balloon-borne sondes. Between 20 and $60 \mathrm{~km}$, OMPS ozone profiles typically agree with data from the Microwave Limb Sounder (MLS) v4.2 within 5-10\%, whereas in the lower altitude range the bias becomes larger, especially in the tropics. The comparison of OMPS profiles with ozonesonde
\end{abstract}

measurements shows differences within $\pm 5 \%$ between 13 and $30 \mathrm{~km}$ at northern middle and high latitudes. At southern middle and high latitudes, an agreement within 5-7\% is also achieved in the same altitude range. An unexpected bias of approximately $10-20 \%$ is detected in the lower tropical stratosphere. The processing of the 2013 data set using the same retrieval settings and its validation against ozonesondes reveals a much smaller bias; a possible reason for this behaviour is discussed.

\section{Introduction}

Ozone is one of the most important trace gases in the atmosphere. It is most abundant in the stratospheric ozone layer, which absorbs strong ultraviolet (UV) radiation, heating this atmospheric region and acting as a protective layer against biologically harmful radiation. It plays a crucial role in the radiative budget of the stratosphere, determines the stratospheric temperature profile and impacts atmospheric circulation and climate. Because of its relevance to both science and society, ozone-related research expanded after the discovery of the springtime ozone hole in Antarctica and the subsequent recognition that man-made release of chlorofluorocarbon compounds depletes the stratospheric ozone layer (Molina and Rowland, 1974; Farman et al., 1985). Although nowadays the stratospheric ozone chemistry is generally well understood, there are still several issues to be clarified. These are related to the expected ozone recovery after the adoption of the Montreal protocol, stratospheric circulation and temperature responses to the increase in greenhouse gases (Li et al., 2009) as well as long-term ozone trends. For example, Solomon et al. (2016) focused their at- 
tention on the Antarctic region, investigating possible signatures of ozone healing. Having analysed observations collected each September since 2000, the authors suggested that the fingerprints of ozone recovery can be identified in both the increase in its column amount and in the decrease in the areal extent of the ozone hole. The issues related to changes in the Brewer-Dobson circulation (BDC), possibly linked to climate changes, have been investigated by several studies which consider the ozone concentration in the lower stratosphere a good proxy with which to track changes in the stratospheric circulation. Among them, Aschmann et al. (2014) used combined ozone time series from satellite instruments and ozonesondes to investigate changes in BDC after the beginning of the century and identified an asymmetry in the northern and southern branches. Stiller et al. (2017) suggested a shift in the subtropical mixing barriers as an explanation.

For all these kinds of studies, reliable long-term data sets are needed from both ground-based and satellite instruments. Recent attempts to consistently merge a large number of different data sets into long-term time series are reported by Froidevaux et al. (2015) and Davis et al. (2016), both including species other than ozone. Steinbrecht et al. (2017) and Sofieva et al. (2017) focused on ozone trends, revealing a global statistically significant increase in its amount after 2000 above $35 \mathrm{~km}$. Other authors, such as Kyrölä et al. (2013), Eckert et al. (2014), Gebhardt et al. (2014) and Nedoluha et al. (2015), pointed out an unexpected decadal negative trend in the ozone abundance in the upper tropical stratosphere.

During the last few decades, several remote-sensing observation techniques have been used to derive ozone concentrations from the troposphere up to the mesosphere (Hassler et al., 2014). Following the birth of the space age, instrumentation of different kinds began to be developed. Space-borne remote-sensing measurements in the ultraviolet-visible (UVVis) spectral range have traditionally been of two types: nadir viewing and solar occultation spectrometers. The former instruments point downward and are characterized by good horizontal coverage, whereas the latter look directly into the solar disk, featuring good vertical resolution and a strong signal. The limb sounding technique, widely used by more recent satellite instruments, combines the advantages of these two: the long path through the atmosphere provides high sensitivity to trace gases and the variation of the observation angle enables a better vertical resolution with respect to the nadir geometry, featuring a much higher horizontal sampling compared to the occultation measurements. Limb observation geometry has also been used to measure scattered solar radiance and/or atmospheric emission in the infrared (IR) and microwave spectral regions. Using the scattered solar light, only measurements during daylight are possible, whereas, using the emission signatures, observations can be performed during both day and night. The accuracy/sensitivity of limb measurements decreases with altitude in the lower strato- sphere and troposphere, as the increasing optical thickness along the line of sight leads to a saturation of the measured signal. The presence of clouds in the field of view acts as an additional limitation.

The limb scatter technique was successfully exploited for the first time by the LORE-SOLSE (Limb Ozone Retrieval Experiment - Shuttle Ozone Limb Sounding Experiment) instrument, launched in 1997 by NASA. Two instruments followed this mission: the Optical Spectrograph and InfraRed Imager System (OSIRIS), launched in February 2001 (Llewellyn et al., 1997), and the SCanning Imaging Absorption spectroMeter for Atmospheric CHartographY (SCIAMACHY), launched in March 2002 (Burrows et al., 1995; Gottwald and Bovensmann, 2011). SCIAMACHY made observations in the UV, Vis, near infrared (NIR) and shortwave infrared (SWIR) spectral ranges until April 2012, when the platform-to-ground communication was lost. A few aging satellite instruments, such as OSIRIS and the Microwave Limb Sounder (MLS), are still operating, contributing to the task of continuous monitoring the stratospheric ozone. At the end of 2011, just a few months before the end of ENVISAT lifetime, the Ozone Mapping and Profiler Suite (OMPS) instrument was launched on board the Suomi National Polar-Orbiting Partnership (SNPP) platform and it is still operational (Flynn et al., 2014). The spacecraft has a sun-synchronous orbit with the ascending node at 13:30 local time and flies at a mean altitude of $833 \mathrm{~km}$. Scientific data collection started at the beginning of 2012. OMPS comprises three instruments: the nadir mapper, nadir profiler and limb profiler (LP). Only the latter is of interest for our study (see Flynn et al., 2014, for a review of the full suite).

After the launch of the satellite, the NASA team developed a retrieval chain to derive ozone profiles and many byproducts from OMPS limb observations, which are publicly available. In addition, at the University of Saskatchewan a 2-D geometry retrieval has been applied to OMPS-LP measurements (Zawada et al., 2017).

This paper presents ozone profile retrievals from OMPSLP observations performed at the University of Bremen. The algorithm we use was developed based on the SCIAMACHY v3.0 ozone retrieval (Jia et al., 2015). As the two instruments have very different spectral resolutions and the measurement techniques differ in many respects, e.g. in terms of spectral channels, wavelength ranges, atmospheric/scene sampling and radiance collection, a direct application of the SCIAMACHY retrieval scheme to OMPS-LP measurements was not possible. Although the algorithm presented in this paper has been newly developed, starting from the one used to process SCIAMACHY data, the same radiative transfer model, a similar retrieval approach and the same spectroscopic and atmospheric parameters databases were used to minimize the systematic errors between the data sets. The underlying objective of the study is the creation of a consolidated product and the merging of the OMPS-LP and the SCIAMACHY time series in order to obtain a long-term continuous data set. 
In Sect. 2, the OMPS instrument is introduced: its geometry of observation, relevant characteristics and issues related to the retrieval of ozone are briefly discussed. The third section is focused on the retrieval methodology, starting with a general description of the inversion algorithm used in this work. A more detailed characterization of the retrieval procedure follows, including the applied cloud filter and the approach used to consider aerosol extinction profiles. Section 4 first presents a comparison with the NASA ozone profile retrieval algorithm, then MLS and ozonesonde data sets are used for a validation of our product. The main results, remaining issues and possible future improvements are addressed in the conclusions.

\section{OMPS-LP instrument}

\subsection{General features and main issues}

The main objective of OMPS-LP is to monitor the ozone vertical distribution within the Earth's middle atmosphere at high level of accuracy. It images the Earth's atmosphere by viewing its edge (limb) from space. The closest approach of the sensor line of sight to the Earth's surface is referred to as the tangent point (TP) and the altitude of this point above the Earth's geoid is called the tangent height (TH); the limb geometry is schematically drawn in the left panel of Fig. 1. The OMPS-LP sensor observes the Earth's limb, looking backwards with respect to the flying direction through three vertical slits: the central one is aligned along the nadir track, whereas the other two are cross-track. As shown in the right panel of Fig. 1, the TPs are located about $25^{\circ}$ latitude south of the sub-satellite point. The spacecraft completes $14-15$ orbits per day and the instrument performs normally 180 limb observations (referred to as states) per orbit.

OMPS-LP measures limb scattered radiance in the spectral range of 280-1000 $\mathrm{nm}$. A particular characteristic of this instrument is the use of a prism spectrometer instead of a grating disperser. The employed prism provides a spectral resolution that degrades with wavelength, from $1 \mathrm{~nm}$ in the UV region up to $40 \mathrm{~nm}$ in the NIR. OMPS-LP observes the full altitude range at the same time, without vertical scanning, and radiance is collected by means of a charge-coupled device (CCD). Each slit covers a vertical range of $112 \mathrm{~km}$, the instantaneous vertical field of view of each detector pixel is about $1.5 \mathrm{~km}$ and the vertical sampling is $1 \mathrm{~km}$ at TP (Jaross et al., 2014). The use of the CCD detector poses a great challenge regarding the dynamic range: indeed, due to the decrease in the atmospheric density, scattered solar radiation from the Earth's limb decreases by at least 5 orders of magnitude along the considered vertical range. Therefore, in order to cover the required dynamic range, four images at a 2-D physical CCD are taken for each slit. The full atmosphere is imaged at two integration times and through a large and a small aperture (Jaross et al., 2014). Ground processing is then needed to select unsaturated signals and combine downlinked pixels from different images in a single radiance file, which is finally resampled and mapped onto a regular grid. The left panel of Fig. 2 shows examples of radiance profiles, displaying the large dynamic range of measured values, whereas the right panel depicts examples of spectral signalto-noise ratio (SNR) at different altitudes. Jumps in this plot are related to the switch between the sampled images, for example, the jump between large and small aperture that occur at $450 \mathrm{~nm}$ (fixed threshold). In the retrieval scheme we take care not to consider spectral ranges crossing this fixed boundary.

One of the most important issues that affects the quality of the limb scattering technique is the $\mathrm{TH}$ registration. The required high pointing accuracy cannot be directly reached for the OMPS-LP sensor, because the star tracker on board the SNPP satellite is mounted at a distant position from the instrument, so that thermal effects and misalignments of the instrument focal plane play an important role.

To solve this problem, several pointing corrections are established during the level $1 \mathrm{~b}$ gridded (L1G) data processing, as described in Moy et al. (2017):

1. fixed adjustments between 1 and $2 \mathrm{~km}$, depending on the slit;

2. TH variation related to the heating up of the instrument, as it approaches northern midlatitudes;

3. dynamic $\mathrm{TH}$ variation within each orbit, characterized by an almost linear dependence with state number.

While the first two are implemented in the current v2.5 version of L1G data, a satisfactory explanation for the latter variation still has to be found and this effect is currently not accounted for. However, following NASA recommendations in DeLand et al. (2017), we implemented a linear TH adjustment as a function of latitude, with values ranging from $+300 \mathrm{~m}$ at the South Pole to $-100 \mathrm{~m}$ at the North Pole.

The second important phenomenon that affects the accuracy of the limb radiance is the stray light. Stray light describes photons that are registered by the detector at wavelengths or altitudes which they do not belong to. For example, with multiple images on a single detector, photons from the IR part of one slit can be scattered into the UV part of the neighbouring image. This problem was reduced both through a thorough study of the point spread function during the prelaunch operations and the careful application of cut-off filters at the focal plane (Jaross et al., 2014). Stray light is mainly an issue at high altitudes, with levels that are usually less than $10 \%$ of the measured value.

Transient events can affect the instrument reliability: energetic charged particles can penetrate through the CCD shielding and cause transients in pixel signal. These events are frequent in the South Atlantic anomaly. 
(a)

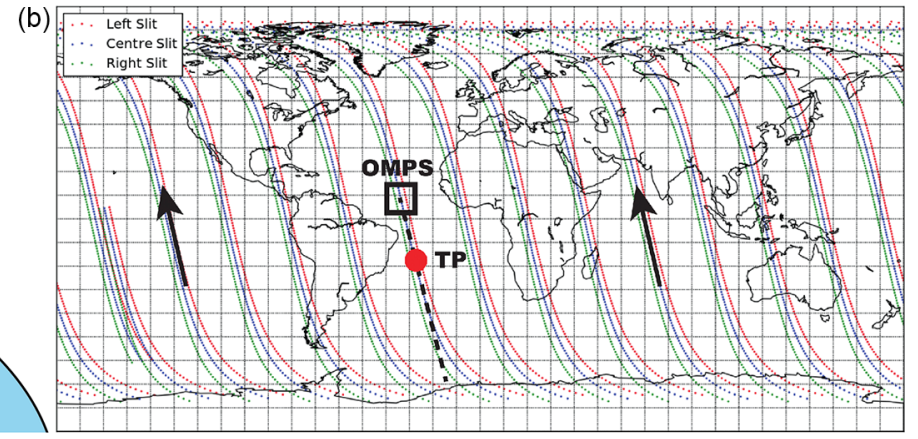

Figure 1. (a) Schematic diagram of the viewing geometry of a satellite limb observation, showing the tangent point (TP) and its height above the Earth or the tangent height (TH). (b) OMPS daily orbits and observation geometry sketch; black arrows indicate the satellite flight direction and the red dot approximately locates the tangent point (TP) (adapted from Bhartia et al., 2013).

(a)

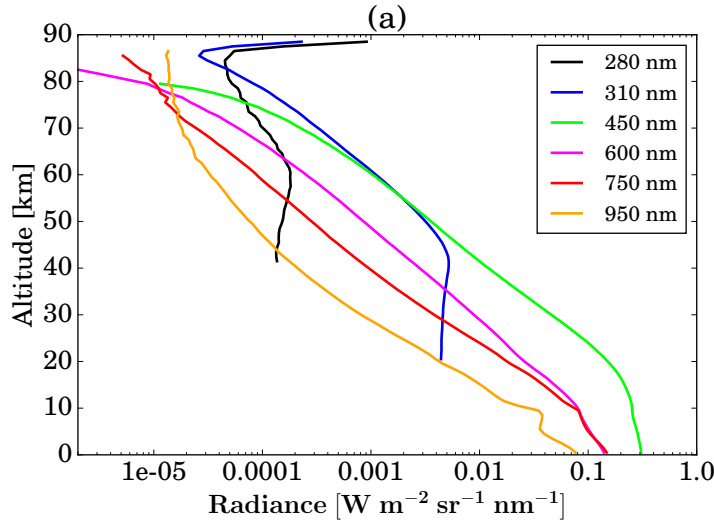

(b)

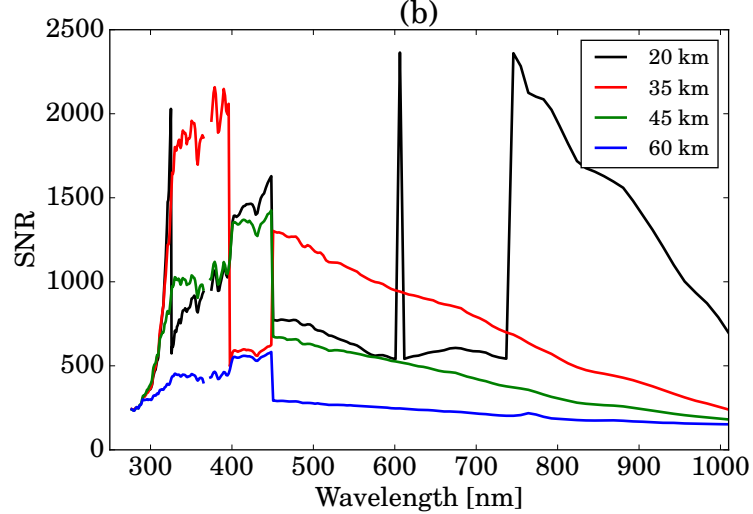

Figure 2. (a) Example of OMPS-LP radiance profiles at some selected wavelengths; (b) OMPS-LP signal-to-noise ratio (SNR) at different tangent heights.

\subsection{OMPS-LP observation geometry}

Several angular coordinates are needed in the retrieval algorithm to correctly describe the observation geometry; satellite azimuth $(\varphi)$, solar azimuth $\left(\varphi_{0}\right)$ and solar zenith angle $\left(\psi_{0}\right)$ at the TP are reported for three THs $(25,35$ and $45 \mathrm{~km})$ in the L1G data files and are used to define the geometry of the observation. The solar zenith angle $\left(\psi_{0}\right)$ is defined as the angle between the local vertical at the TP and the sun pointing vector. The azimuth angles, $\varphi$ and $\varphi_{0}$, are defined as the angles between the direction of the North Pole and the projections of the solar beam and the instrument line of sight, respectively, on the plane orthogonal to the normal vector at the TP.

By combining azimuth and zenith angles, the scattering angle $\theta$ at the TP can be computed as

$\cos (\theta)=\sin \left(\psi_{0}\right) \cos \left(\varphi-\varphi_{0}\right)$.

This is an important quantity that defines the scattering geometry. In Fig. 3 values of scattering angles together with solar zenith angles are plotted as a function of latitude for three OMPS orbits in different seasons. Solar zenith angles are shown as solid lines, with symmetric values with respect to the equatorial region, whereas scattering angles are plotted as dashed lines. Only solar zenith angles less than $80^{\circ}$ are plotted and the ozone retrieval is run only for the corresponding states, usually 140 per orbit, to avoid high straylight levels. The latitude coverage in different seasons can be assessed from the figure.

\section{Retrieval method}

\subsection{Theoretical basis}

The retrieval of ozone profiles is performed using the regularized inversion technique with the first-order Tikhonov constraints (Tikhonov, 1963; Rodgers, 2000). The non-linearity of the inverse problem is accounted for using an iterative approach. The forward modelling takes into consideration atmospheric multiple scattering in the framework of the approximate spherical solver of the SCIATRAN radiative transfer model (Rozanov et al., 2014). Thereby, the CDI (combined differential integral) approach is employed to solve the 


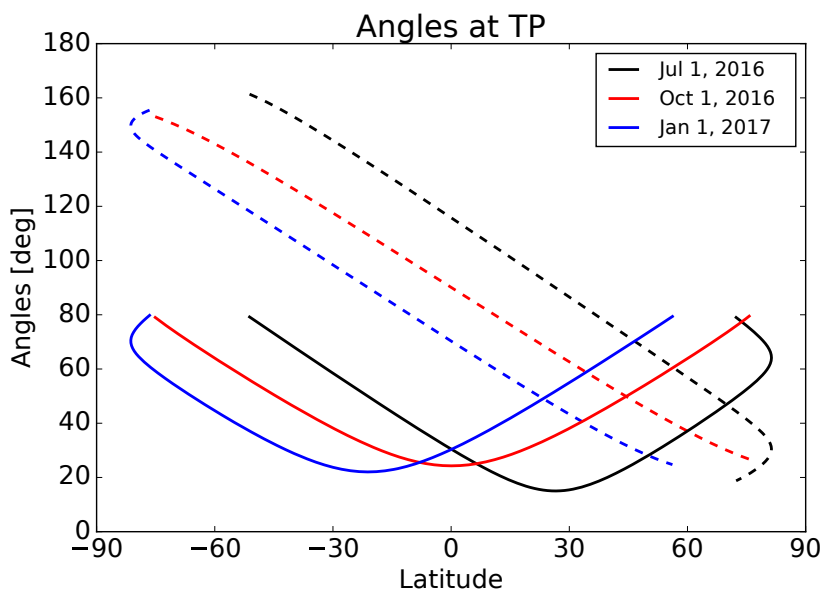

Figure 3. Solar zenith angles (solid lines) and scattering angles (dashed lines) at the TP along three OMPS orbits on the following dates: 1 July 2016, 1 October 2016 and 1 January 2017.

radiative transfer equation: first, the entire radiation field is calculated in the pseudo-spherical approximation for a set of solar zenith angles using the finite difference method. Pseudo-spherical approximation means that the direct solar beam is traced in a fully spherical geometry while a planeparallel atmosphere is assumed to calculate the scattered light. Then, an integration along the line of sight is carried out in a spherical geometry, i.e. intersecting a spherical shell atmosphere, also accounting for the atmospheric refraction. Thereby the single-scattering contribution is calculated in a spherical geometry, while the multiple scattering contribution at each point along the line of sight is approximated by an angular integration of the pseudo-spherical radiative field calculated at the first step (Rozanov et al., 2000). Weighting functions are calculated using the same method as for the radiance, but considering only the single-scattering contribution.

Linearizing the forward model around an initial guess state $\boldsymbol{x}_{0}$, the general equation that has to be solved can be written as

$\boldsymbol{y}=\boldsymbol{y}_{0}+\mathbf{K}\left(\boldsymbol{x}-\boldsymbol{x}_{0}\right)+\boldsymbol{\epsilon}$,

where $\boldsymbol{y}$ is the measurement vector, $\boldsymbol{y}_{0}$ is the simulated spectrum, $\mathbf{K}$ is the linearized forward model operator represented by the weighting function matrix, $\boldsymbol{x}$ is the state vector and $\epsilon$ represents errors of any kind. Following Rodgers (2000), the solution of Eq. (2) can be estimated iteratively. Taking into consideration that in our algorithm the retrieval is performed from a zero a priori profile, the iterative step $i+1$ can be expressed as

$\boldsymbol{x}_{i+1}=\left(\mathbf{K}_{i}^{T} \mathbf{S}_{\epsilon}^{-1} \mathbf{K}_{i}+\mathbf{S}_{0}+\mathbf{S}_{1}^{T} \boldsymbol{\gamma} \mathbf{S}_{1}\right)^{-1} \mathbf{K}_{i}^{T} \mathbf{S}_{\epsilon}^{-1}\left(\boldsymbol{y}-\boldsymbol{y}_{i}+\mathbf{K}_{i} \boldsymbol{x}_{i}\right)$.

Here, $\mathbf{S}_{\epsilon}$ is the measurement noise covariance matrix. $\mathbf{S}_{0}$ is the diagonal matrix optimized to constrain the solution within physically meaningful values and minimize a possible negative bias caused by the use of a zero a priori profile. The effect of the chosen matrix is significant only at tropical low altitudes and globally at high altitudes, where the ozone concentration is very small. Finally, $\mathbf{S}_{1}$ is the first-order derivative matrix ( $\mathbf{S}_{1}^{T} \boldsymbol{\gamma} \mathbf{S}_{1}$ is the first-order Tikhonov term). The diagonal matrix $\boldsymbol{\gamma}$ contains altitude-dependent weights, used to constrain the smoothness of the retrieved profile. In the following, the sum $\mathbf{S}_{0}+\mathbf{S}_{1}^{T} \boldsymbol{\gamma} \mathbf{S}_{1}$ will be named $\mathbf{S}_{r}$.

\subsection{Algorithm implementation}

For the ozone vertical profile retrieval from OMPS-LP, four spectral segments are selected: three in the UV spectral region (Hartley and Huggins bands) and one in the visible range (Chappuis band). The former ranges are sensitive to the upper stratospheric ozone, whereas the latter is sensitive to the lower stratospheric region, where the peak number density occurs. In order to avoid strong absorption bands of water vapour and $\mathrm{O}_{2}$, wavelengths in the ranges 580.0 607.0 and $620.0-635.0 \mathrm{~nm}$ are rejected. A complete treatment of these absorption features requires line-by-line calculations, which are computationally expensive. The altitude range over which the retrieval is performed spans between 12 and $60 \mathrm{~km}$ above sea level. The vertical grid is fixed throughout the processing and covers the retrieval range at evenly spaced steps of $1 \mathrm{~km}$. To prepare the measurement vector, limb radiance in each spectral interval is normalized with respect to a limb measurement at an upper TH in order to provide a self calibration of the instrument and reduce the effect of surface/cloud reflectance. In addition, for longer wavelength intervals, a polynomial is subtracted from the logarithm of the normalized radiance in order to remove slowly variable spectral features, e.g. caused by Rayleigh or aerosol scattering (Rozanov et al., 2011). Equation (4) explicitly shows the measurement vector at the $j$ th $\mathrm{TH}$ and details about spectral segments and TH normalizations are listed in Table 1. The last column provides information about the subtracted polynomial in the measurement vector: first order in the visible range, zeroth order or no polynomial in the UV region.

$\boldsymbol{y}_{j}=\log \left(\frac{\boldsymbol{I}_{\mathrm{TH}_{j}}}{\boldsymbol{I}_{\mathrm{TH}_{\mathrm{norm}}}}\right)-\boldsymbol{P}_{n}$

In the forward model, the radiation is calculated taking into account $\mathrm{O}_{3}, \mathrm{NO}_{2}$ and $\mathrm{O}_{4}$, which have spectral signatures in the selected spectral ranges. Cross sections of these gases are taken from Serdyuchenko et al. (2014), Bogumil et al. (2000) and Hermans (2011), respectively. Cross sections are convolved to the OMPS-LP spectral resolution beforehand. Ancillary pressure and temperature profiles are taken from the Global Modelling and Assimilation Office (GMAO) interpolated data set, provided by the NASA team together with OMPS-LP L1G radiances. 
Table 1. List of the spectral segments considered for the ozone retrieval with corresponding altitude ranges, THs used for the normalization and the order of the subtracted polynomial ( - means that no polynomial is subtracted).

\begin{tabular}{lrrr}
\hline $\begin{array}{l}\text { Altitude } \\
\text { range }(\mathrm{km})\end{array}$ & $\begin{array}{r}\text { Spectral } \\
\text { segment }(\mathrm{nm})\end{array}$ & $\begin{array}{r}\text { Normalization } \\
\text { TH }(\mathrm{km})\end{array}$ & $\begin{array}{r}\text { Polynomial } \\
\text { order }\end{array}$ \\
\hline $46-60$ & $285-302$ & 63.5 & - \\
$35-46$ & $305-313$ & 52.5 & - \\
$31-36$ & $322-331$ & 47.5 & 0 \\
$12-33$ & $508-660^{*}$ & 42.5 & 1 \\
\hline
\end{tabular}

* 580.0-607.0 and 620.0-635.0 nm ranges are rejected.

Before the main retrieval procedure, a shift and squeeze correction is applied to the modelled spectrum in the Chappuis band with respect to the measured one. This preprocessing is performed for each observation at each $\mathrm{TH}$ independently and is introduced to account for issues related to the spectral calibration and possible thermal expansion of the detector. Typical values for the spectral shift are inside the range $[+1,+4] \mathrm{nm}$ for the first point of the interval and $[-2,+1] \mathrm{nm}$ for the last spectral point. Due to the relatively low spectral resolution of the instrument, the differential absorption structure in the Huggins band is largely smoothed out and the UV retrieval uses either normalized radiances themselves or their slopes. As a consequence, the influence of a possible spectral misalignment is rather small and the shift and squeeze algorithm is not applied in the UV. In the pre-processing procedure, we obtain the $\mathbf{S}_{\epsilon}$ matrix from the fit residuals, fitting absorption features of all relevant gases in the selected spectral windows.

The inversion scheme is then iteratively run employing Eq. (3). The state vector $\boldsymbol{x}_{i+1}$, containing the retrieved ozone vertical distribution at each $i$ th iteration, is expressed in terms of the volume mixing ratio (VMR), which is more suitable for use with smoothing constraints. The smoothing weights, i.e. square roots of the diagonal elements of $\boldsymbol{\gamma}$, linearly increase with height above $45 \mathrm{~km}$ and remain constant below.

Surface albedo is simultaneously retrieved with ozone using the sun-normalized radiance provided in the L1G data. Two spectral fitting windows at THs around $38 \mathrm{~km}$ are employed at 355-365 and 455-470 nm, where ozone absorption is weak.

\subsection{Cloud filter}

A cloud filter is applied during the ozone retrieval to reject THs at which a cloud is present in the field of view of the instrument. The applied algorithm is based on the colour index ratio (CIR) concept (Eichmann et al., 2016), using OMPS$\mathrm{LP}$ radiance at 754 and $997 \mathrm{~nm}$. The colour index (CI) is defined as the ratio of the radiance at the two chosen wavelengths for the same OMPS-LP spectrum. The CI can be used to detect the presence of scattering particles in the field of

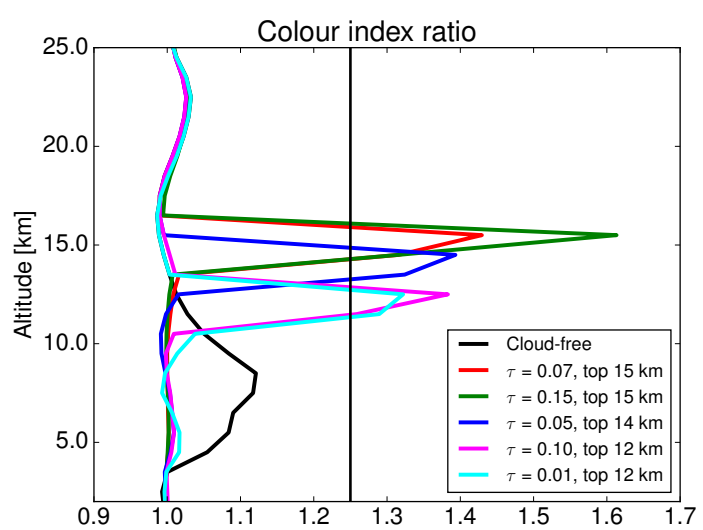

Figure 4. Example of colour index ratios for different simulations of ice clouds. Top of the cloud and optical depth $(\tau)$ ranges are chosen to simulate the impact of thin cirrus clouds in the upper troposphere.

view, since we know the expected ratio for a cloud-free atmosphere. First, the CI is calculated at all THs, then the CIR is obtained as

$\operatorname{CIR}\left(z_{\mathrm{TH}}\right)=\frac{\mathrm{CI}\left(z_{\mathrm{TH}}\right)}{\mathrm{CI}\left(z_{\mathrm{TH}}+\Delta z_{\mathrm{TH}}\right)}$,

where $\Delta z_{\mathrm{TH}}$ is the vertical grid step of $1 \mathrm{~km}$. An example of the results for simulated clouds is reported in Fig. 4: cirrus clouds consisting of hexagonal crystals with an optical depth between 0.01 and 0.15 are taken into consideration. Since the ozone retrieval is run above $12 \mathrm{~km}$, we are generally not interested in liquid water clouds.

The threshold chosen to flag a TH as cloudy is 1.25 . This technique was also applied to SCIAMACHY measurements with a different threshold (Eichmann et al., 2016). At the considered wavelengths the measured radiation is related to the scattered light from molecules, aerosol or cloud particles. A question may arise regarding the inability of such an approach to distinguish between high aerosol loads and cirrus clouds. Future investigations will focus on a comparison between the CIR filter and aerosol profiles retrieved as described in the next subsection.

A different approach was used to detect polar mesospheric clouds (PMCs). The presence of PMCs can affect limb radiance down to $40 \mathrm{~km}$, causing an interference with ozone retrievals. Therefore, we screen out the PMC-contaminated profiles in this study using the PMC detection flag at high latitudes above $50^{\circ} \mathrm{N}$ and below $50^{\circ} \mathrm{S}$ where the PMC occurrence is most frequent. PMCs are detected using the radiance profile at $353 \mathrm{~nm}$ and several conditions on radiance and its gradients. In the absence of PMCs, radiance is expected to decrease monotonically with height above $40 \mathrm{~km}$. As a consequence, the ozone profile is flagged if the radiance between 40 and $80 \mathrm{~km}$ increases with altitude or its gradient increases more then $50 \%$ between at least two consecutive layers. 


\subsection{Aerosol treatment}

The aerosol extinction coefficient is retrieved by employing the general approach as used for SCIAMACHY v1.4 stratospheric aerosol extinction product (Rieger et al., 2017). As a consequence of a coarser spectral resolution, the radiance measured at $750 \mathrm{~nm}$ is affected by the $\mathrm{O}_{2}$ absorption band. For this reason the OMPS aerosol extinction coefficient retrieval uses the radiance at $869 \mathrm{~nm}$ instead of $750 \mathrm{~nm}$, as done for SCIAMACHY and OSIRIS. Stratospheric aerosol extinction is retrieved in the altitude range from 10.5 to $33.5 \mathrm{~km}$. The measurement at $34.5 \mathrm{~km}$ is used as the reference; the effective Lambertian albedo is simultaneously retrieved using the sun-normalized spectrum at $34.5 \mathrm{~km}$. In order to smooth spurious oscillations, the first-order Tikhonov regularization is employed. Scattering phase functions are calculated using Mie scattering theory. The particle size distribution is assumed to be log-normal with a median radius $\left(r_{g}\right)$ of $0.08 \mu \mathrm{m}$ and distribution width parameter $(\sigma)$ of 1.6. The corresponding probability distribution function is given by the following equation:

$\frac{\mathrm{d} n(r)}{\mathrm{d} r}=\frac{N}{\sqrt{2 \pi} \ln (\sigma) r} \exp \left(\frac{\left(\ln \left(r_{g}\right)-\ln (r)\right)^{2}}{2 \ln ^{2}(\sigma)}\right)$.

The aerosol particles are assumed to be sulfuric droplets with $0 \%$ relative humidity in the surrounding atmosphere. Below $10 \mathrm{~km}$ and above $46 \mathrm{~km}$ the aerosol load is set to zero. The refractive indexes are calculated using the Optical Properties of Aerosols and Clouds (OPAC) database (Hess et al., 1998). Before using the retrieved aerosol product, altitudes downwards from the detected cloud top height are rejected and each profile is extrapolated by the scaled a priori profile. The scaling factor is derived by averaging three altitude levels above the cloud.

Because of the strong forward peak of the aerosol scattering phase function, it is particularly important to accurately model the aerosol scattering at high northern latitudes where the scattering angle is small (refer to Fig. 3).

\section{Results}

In this section we present the results of the processing, for the whole of 2016. Version 2.5 of OMPS-LP L1G data has been used, which was improved in terms of stray-light treatment and pointing corrections in comparison to the previous version, as described in Sect. 2.1. Retrievals were performed using data only from the central slit of the instrument because the lateral slits are still considered to suffer from pointing issues.

\subsection{Retrieval characterization and error analysis}

The information content of the measurements as well as the sensitivity of the retrieval can be analysed using the averag- ing kernels (A) and the covariance of the retrieval noise $\left(\mathbf{S}_{m}\right)$ obtained respectively as follows (Rodgers, 2000):

$$
\begin{aligned}
& \mathbf{A}=\left(\mathbf{K}^{T} \mathbf{S}_{\epsilon}^{-1} \mathbf{K}+\mathbf{S}_{r}\right)^{-1} \mathbf{K}^{T} \mathbf{S}_{\epsilon}^{-1} \mathbf{K} \\
& \mathbf{S}_{m}=\left(\mathbf{K}^{T} \mathbf{S}_{\epsilon}^{-1} \mathbf{K}+\mathbf{S}_{r}\right)^{-1} \mathbf{K}^{T} \mathbf{S}_{\epsilon}^{-1} \mathbf{K}\left(\mathbf{K}^{T} \mathbf{S}_{\epsilon}^{-1} \mathbf{K}+\mathbf{S}_{r}\right)^{-1} .
\end{aligned}
$$

The square root values of the diagonal elements of the retrieval noise covariance matrix $\mathbf{S}_{m}$ will be referred to as the theoretical precision of the retrieval. Following von Clarmann (2014), we do not include smoothing errors in the retrieval error budget. The vertical resolution of the retrieved profile is computed as the inverse of the diagonal elements of the averaging kernel matrix, multiplied by the altitude layer width. Examples of averaging kernels, vertical resolution and theoretical precision are plotted in Fig. 5.

The left panel shows averaging kernels (AKs) for an example profile at $30^{\circ} \mathrm{N}$. For the sake of clarity, only each fourth $\mathrm{AK}$ is plotted. The middle and right panels show the latitudinal dependence of the vertical resolution and precision, respectively, for 1 day of OMPS measurements (15 September 2016). Below $30 \mathrm{~km}$ the actual vertical resolution of the retrieval scheme is typically about $2-3 \mathrm{~km}$ worsening around $33 \mathrm{~km}$, where the transition between the UV and Vis spectral ranges occurs. The best vertical resolution of the profiles is achieved around $45 \mathrm{~km}$, whereas above $50 \mathrm{~km}$ it is coarser due to the increasing Tikhonov parameter. The theoretical precision of the retrieved ozone profiles does not show any significant dependence on the solar zenith angle (or latitude) above $25 \mathrm{~km}$. It lies in the range of $1-4 \%$ up to $60 \mathrm{~km}$ and tends to increase at lower altitudes, particularly in the tropical upper troposphere - lower stratosphere (UTLS) region: at these levels, the ozone concentration drops significantly and the retrieval precision degrades, with relative errors up to $10-30 \%$. This purely random uncertainty is expected to be significantly reduced when averaging several profiles, as done in the validation section of this paper. For example, considering 10000 profiles and a relative precision of $30 \%$ for each single profile, the random uncertainty on the averaged profile is equal to $0.3 \%$. Therefore, the random noise error is rather negligible when analysing the validation results.

\subsection{Comparison with NASA OMPS-LP ozone product}

To retrieve ozone profiles from OMPS-LP observations, the NASA team implemented the Environmental Data Record algorithm, based on the optimal estimation approach with a priori constraints. In this procedure, a series of secondary parameters such as surface albedo, cloud height and TH correction are derived before the main retrieval of ozone profiles (Rault and Loughman, 2013). Two spectral ranges are used for the latter task: UV wavelengths between 29.5 and $52.5 \mathrm{~km}$ and wavelengths in the Chappuis band between 12.5 and $37.5 \mathrm{~km}$. The normalization of the radiance is performed with respect to high-altitude $\mathrm{TH}$ measurements: $55.5 \mathrm{~km}$ in UV and $40.5 \mathrm{~km}$ in Vis. The measurement vector is obtained 

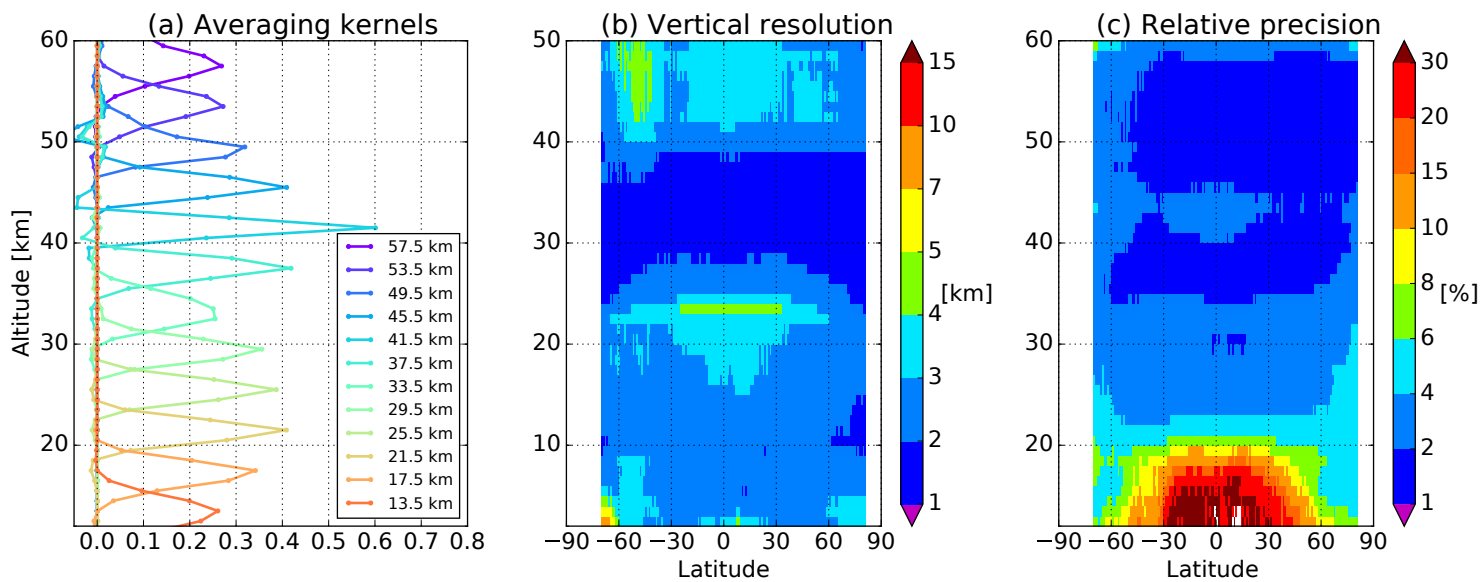

Figure 5. From (a) to (c), examples of averaging kernels (plotted every $4 \mathrm{~km}$ for sake of clarity), vertical resolution and theoretical precision of the retrieval scheme. AKs are plotted for a measurement at $30^{\circ} \mathrm{N}$, whereas vertical resolution and theoretical precision are shown as a function of latitude, i.e. solar zenith angle, for 1 day (15 September 2016).

Table 2. Wavelengths used in the NASA-OMPS ozone retrieval, according to DeLand et al. (2017).

\begin{tabular}{ll}
\hline Parameters & Values \\
\hline Doublet $\lambda_{0}$ & $353 \mathrm{~nm}$ \\
Triplet $\lambda_{l}$ & $510 \mathrm{~nm}$ \\
Triplet $\lambda_{r}$ & $675 \mathrm{~nm}$ \\
Wavelength used in UV $(\mathrm{nm})$ & $302,312,322$ \\
Wavelength used in Vis $(\mathrm{nm})$ & 600 \\
\hline
\end{tabular}

using the doublet and triplet methods, respectively, for the Hartley-Huggins and Chappuis bands; more details are given in Table 2. An additional TH correction is applied by the NASA team on L1G data, as described in Sect. 2.1 and in the release notes on level 2 (L2) data (DeLand et al., 2017). The quality flag related to the South Atlantic anomaly is taken into consideration for the following comparison (Kahn and Kowitt, 2015).

In version 2.5 of NASA L2 data, independent profiles for the Vis and UV retrievals are provided. Figure 6 shows a comparison between NASA-OMPS retrievals and our results (in the following called IUP-OMPS), considering the two retrieved profiles independently. Panel (a) presents an example of averaged profiles in terms of the number density for the tropics. In panels (b) and (c), relative differences are shown for the tropical region and for southern and northern middle and high-latitude bands. Throughout the paper, relative differences are computed as

Rel diff $=\frac{2 \cdot(\text { IUP-OMPS }- \text { reference data set })}{(\text { IUP-OMPS }+ \text { reference data set })} \cdot 100$.

Considering the discrepancies with the NASA Vis retrieval, in (a), excellent agreement within $3 \%$ is achieved in the tropical region above $20 \mathrm{~km}$. At northern midlatitudes the agreement is slightly worse, with differences up to $5 \%$ between 18 and $27 \mathrm{~km}$ and $5-9 \%$ above $28 \mathrm{~km}$. This positive bias slightly increases towards northern polar regions. The differences at the southern midlatitudes show similar altitude behaviour to those in the Northern Hemisphere but have a smaller magnitude. Towards the South Pole, we notice the worst agreement is above $30 \mathrm{~km}$. These discrepancies are possibly related to the merging of the spectral information from UV and Vis ranges at these altitudes in IUP retrievals. In the UTLS region we notice larger differences between the two profiles, especially in the tropics, where the ozone concentration in this altitude range is very low. As a consequence, specific settings of the two retrievals such as spectral ranges, a priori values, aerosol and cloud retrievals play a larger role and are the most probable reason for the observed disagreement. Unfortunately, it is not possible to identify and relate each discrepancy at different altitudes to specific settings of the two algorithms: a stepwise adjustment of the settings is not always feasible, because the intermediate retrieval versions would result in oscillating or nonconverging solutions.

Considering the NASA UV retrieval, the differences shown in panel (c) are very similar for all latitude bands and an agreement within $\pm 5 \%$ is observed at most altitudes, except around $50 \mathrm{~km}$ in the tropics and at $45 \mathrm{~km}$ at northern middle and high latitudes, where the relative differences increase to $5-8 \%$. This may be related to the different usage of UV spectral ranges or TH normalization.

The jump between Vis and UV retrievals, evident when comparing panels (b) and (c), especially at northern midlatitudes, is also reported by the NASA team in the corresponding release notes (DeLand et al., 2017): a preliminary comparison of their results with MLS assesses that values retrieved in the Vis range in the overlapping region (29.5- 

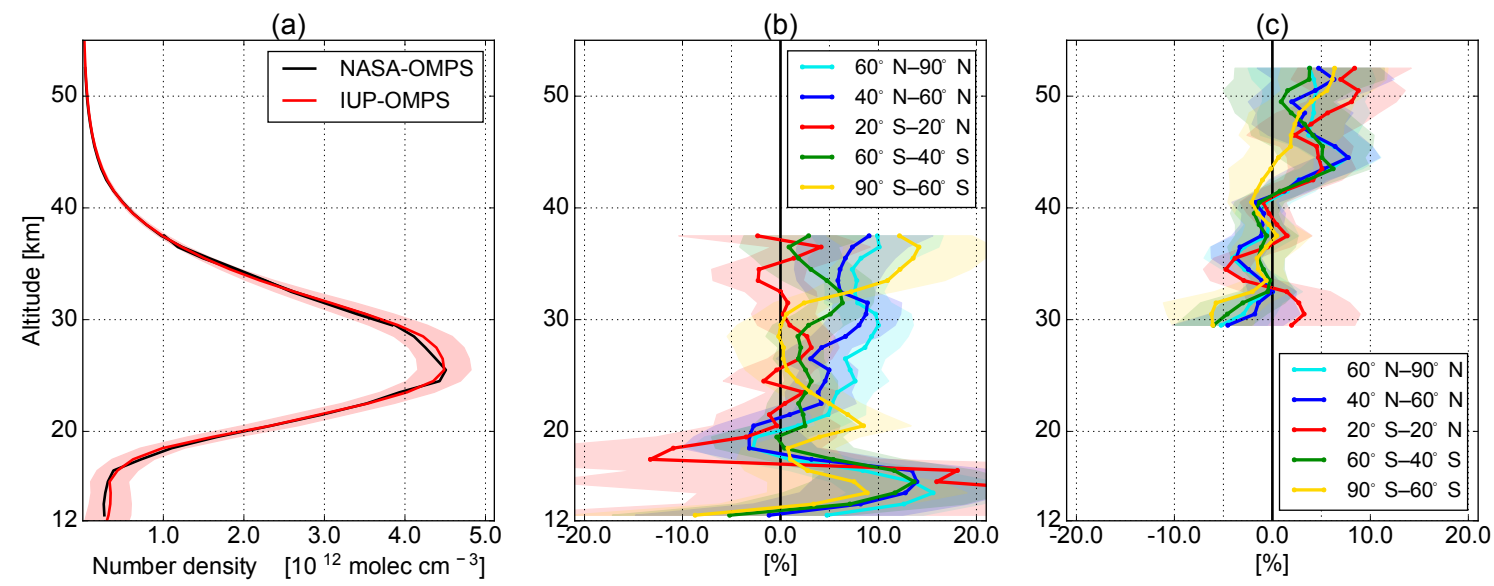

Figure 6. (a) IUP-OMPS and NASA-OMPS retrieved number density profiles averaged in the tropical region. (b, c) The relative differences (Eq. 9) for the Vis and UV retrievals, respectively, are shown in five latitudinal bands $\left(60-90^{\circ} \mathrm{N}, 40-60^{\circ} \mathrm{N}, 20^{\circ} \mathrm{S}-20^{\circ} \mathrm{N}, 60-40^{\circ} \mathrm{S}\right.$ and $\left.90-60^{\circ} \mathrm{S}\right)$, with corresponding standard deviations as shaded areas.

$37.5 \mathrm{~km})$ are systematically lower at middle and high latitudes.

\subsection{Comparison with MLS}

The MLS instrument was launched on board the Aura satellite in July 2004 to observe the thermal emission from atmospheric trace gases in the millimetre/sub-millimetre spectral range. It scans the Earth's limb 240 times per orbit, providing retrievals of daytime and night-time profiles of several gases. For a detailed description of the MLS instrument refer to Waters et al. (2006). In this paper, the version 4.2 of MLS L2 data is used for the validation. Quality flags and recommendations reported in Livesey et al. (2017) are taken into consideration for the following analysis. Because of the large amount of available data, strict criteria are applied to collocate the measurements. The geographic distance between the centres of the two instrument footprints is limited to be within $1^{\circ}$ latitude and longitude and the time difference is required to be within $6 \mathrm{~h}$. In addition, the difference in the potential vorticity at $20.5 \mathrm{~km}$ is required to be less than 5 PVU in order to avoid collocation of measurements inside and outside the polar vortex. Information about potential vorticity is taken form the European Centre for Medium-Range Weather Forecasts (ECMWF) database (ERA-Interim). OMPS-LP states affected by the presence of PMCs and observations at altitudes flagged as cloudy are rejected. In the case of multiple MLS collocations for the same OMPS-LP measurement, only the closest one is taken into consideration. To be consistent with NASA and sonde comparisons, MLS profiles are converted from VMR vs. pressure to number density vs. altitude (using MLS geopotential height), interpolated at the regular altitude grid of IUPOMPS retrieved profiles and are finally zonally averaged. Five latitudinal bands are selected for the comparison: 60 $90^{\circ} \mathrm{N}, 40-60^{\circ} \mathrm{N}, 20^{\circ} \mathrm{S}-20^{\circ} \mathrm{N}, 60-40^{\circ} \mathrm{S}$ and $90-60^{\circ} \mathrm{S}$. Fig- ure 7 shows the averaged profiles for the tropics and northern midlatitudes and the relative differences (Eq. 9) in the five latitudinal bands. Standard deviations are reported in the plots as shaded areas. The number of collocations per band is $\sim 10000$. The zonally averaged relative differences of IUPOMPS with MLS are found to be generally within $5 \%$ between 20 and $58 \mathrm{~km}$ for all latitude bands. In the tropics a fairly constant positive bias of $2-4 \%$ is observed at all altitudes above $28 \mathrm{~km}$. At northern midlatitudes we notice a negative discrepancy of about 6-7\% around $28-30 \mathrm{~km}$, which becomes more evident towards polar regions; up to $58 \mathrm{~km}$ the relative difference exceeds $3 \%$ only at $45 \mathrm{~km}$. At southern midlatitudes IUP-OMPS shows about $5 \%$ higher ozone number density around $25 \mathrm{~km}$, whereas at other altitudes between 20 and $58 \mathrm{~km}$ an agreement within $3 \%$ is achieved. Below $20 \mathrm{~km}$, the agreement with MLS worsens, with relative differences above $20 \%$ in the tropics, even though the absolute difference is rather small (see panel a).

Figure 8 shows the relative differences between IUPOMPS and MLS zonal means in $2.5^{\circ}$ latitude bins as a function of altitude. Three time periods are considered in the panels. In panel (a), showing the whole of 2016, we can see that between 20 and $60 \mathrm{~km}$ the differences are mostly within $\pm 5 \%$ and never exceed $10 \%$ at all latitudes. Starting the discussion of the discrepancies from the bottom of the plots, oscillating differences larger than $30 \%$ are found in the tropical UTLS region. This large discrepancy can be related to several factors such as high dynamic variability of ozone, generally low sensitivity in the lowermost retrieval altitude range or issues with the cloud filtering. As already mentioned, in this region the ozone concentration decreases and the accuracy of the retrieved profiles degrades. Around $28-33 \mathrm{~km}$ a dip in IUP-OMPS ozone values is visible towards the northern high latitudes, especially during winter months (panel c), whereas higher values are found in the tropics: this altitude 

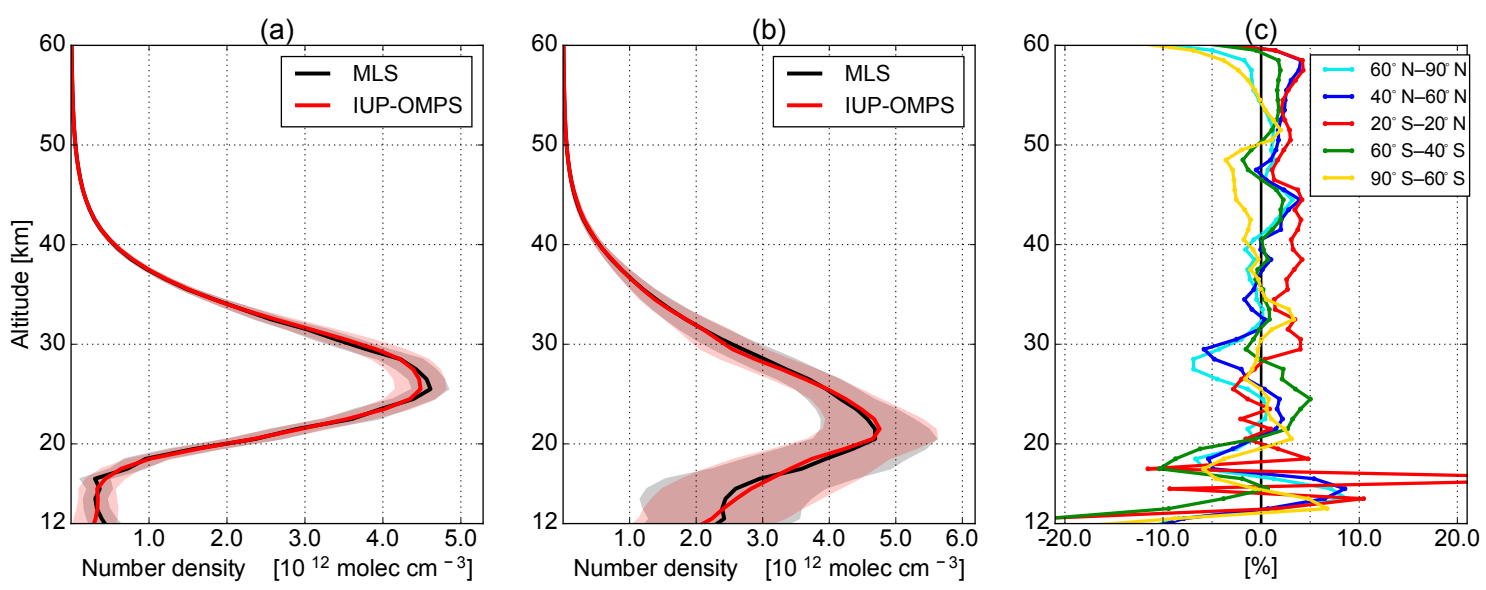

Figure 7. (a, b) Collocated IUP-OMPS retrieved profiles and MLS ozone product in the tropical region and at northern midlatitudes, respectively. (c) Relative difference profiles (Eq. 9) in five latitudinal bands (60-90 ${ }^{\circ} \mathrm{N}, 40-60^{\circ} \mathrm{N}, 20^{\circ} \mathrm{S}-20^{\circ} \mathrm{N}, 60-40^{\circ} \mathrm{S}$ and $90-60^{\circ} \mathrm{S}$ ), with standard deviations shown as shaded areas.
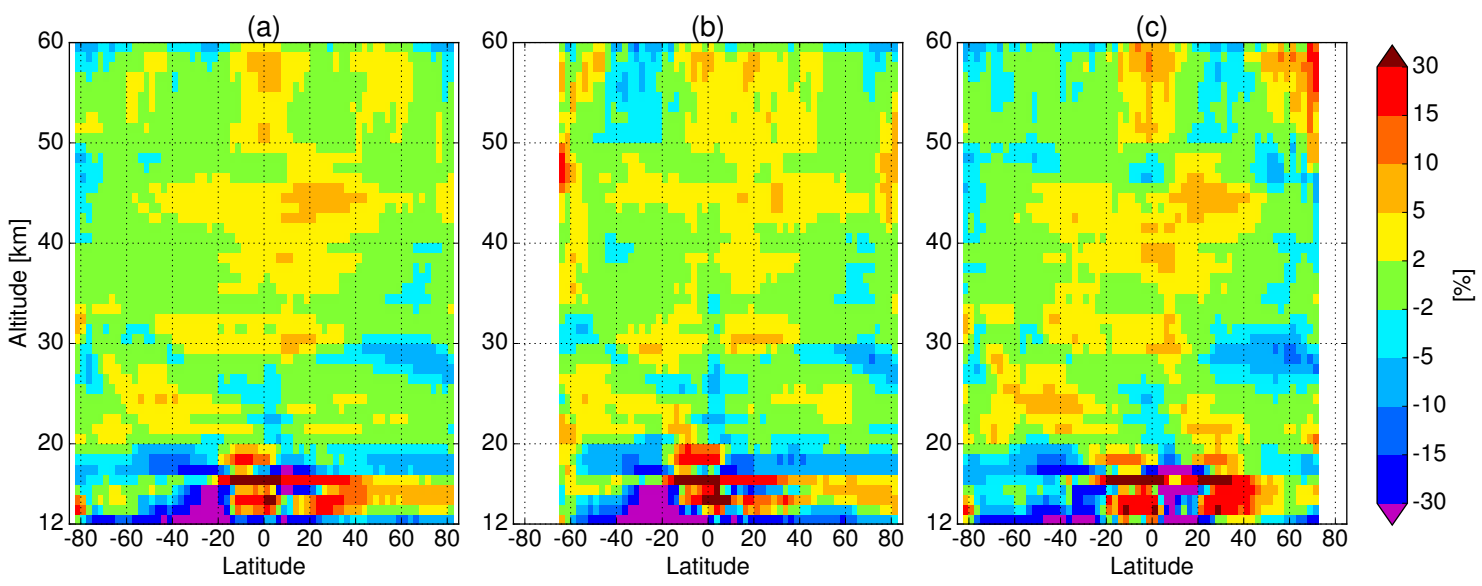

Figure 8. Relative differences (Eq. 9) averaged over $2.5^{\circ}$ latitude bins, plotted as a function of altitude. (a) Whole year; (b) June, July and August; (c) January, February and December.

range corresponds to the overlap region between the contributions from UV and Vis spectral windows and their merging can lead to some inconsistencies. In addition, a non-optimal albedo retrieval could cause biases during winter at northern polar latitudes. Around $45 \mathrm{~km}$, higher values are shown by IUP-OMPS in the tropics and at northern midlatitudes. This issue, already found in Fig. 6c, may be related to a problem in the junction between the spectral ranges in the Hartley and Huggins bands that occurs at $46 \mathrm{~km}$. In panel (c), we also notice a discrepancy in the equatorial region and towards the North Pole above $50 \mathrm{~km}$; this disagreement can be partly related to the stray light affecting the TH used for the normalization.

To summarize, the presented comparison shows a general validity of IUP-OMPS retrieval between 20 and $58 \mathrm{~km}$ in the tropics and down to $15 \mathrm{~km}$ at midlatitudes, even if during dif- ferent seasons the relative bias with respect to MLS may exceed $10 \%$ in some atmospheric regions.

\subsection{Comparison with ozonesondes}

In order to provide a more reliable validation of our product at altitudes below $30 \mathrm{~km}$, we are taking into consideration ozonesonde measurements. Ozonesonde data are obtained from WOUDC (World Ozone and Ultraviolet Radiation Data Centre) and SHADOZ (Southern Hemisphere ADditional OZonesondes, Thompson et al., 2007) archives. We selected more relaxed collocation criteria compared to MLS, because of the sparseness of ozonesonde measurements. Therefore, OMPS-LP measurements are required to be within $5^{\circ}$ latitude and $10^{\circ}$ longitude from the ozonesonde station and within a $\pm 12 \mathrm{~h}$ time span around the sonde launch. For each sonde profile, all collocated OMPS-LP observations are averaged before the comparison. In order to 
(a)

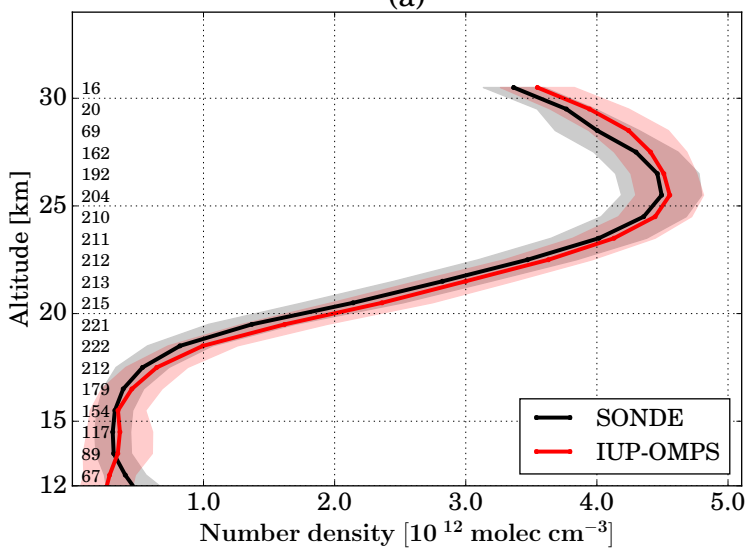

(b)

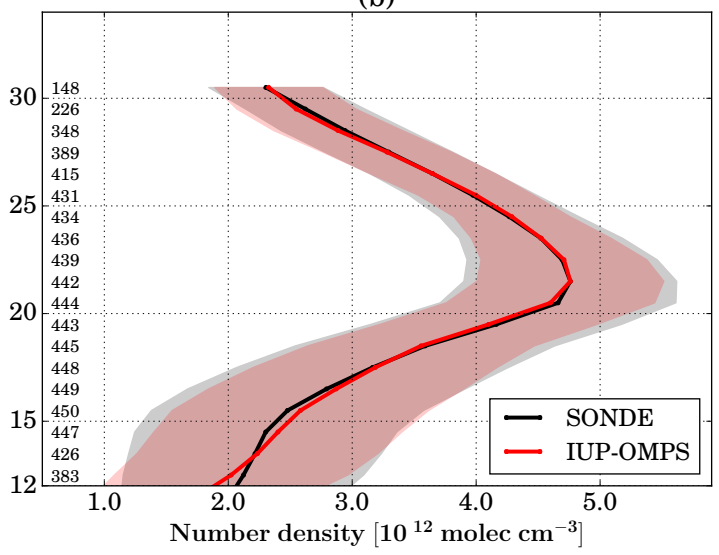

Figure 9. Comparison between collocated IUP-OMPS profiles and ozonesonde measurements in the latitudinal bands $20^{\circ} \mathrm{S}-20^{\circ} \mathrm{N}$ in (a) and $40-60^{\circ} \mathrm{N}$ in panel (b); standard deviations are shown as shaded areas.

account for the different vertical resolution of the compared profiles, ozonesonde measurements are convolved with the AKs of the IUP-OMPS retrieval scheme as follows. First, we calculate the linear interpolation matrix $\mathbf{L}$ to map the low-resolution OMPS profile onto the fine sonde grid. Then this matrix is inverted using the pseudo-inverse formulation (Rodgers, 2000), obtaining $\mathbf{L}^{*}$ as

$\mathbf{L}^{*}=\left(\mathbf{L}^{T} \mathbf{L}\right)^{-1} \mathbf{L}^{T}$.

The ozonesonde high-resolution profile $\boldsymbol{x}_{\text {fine }}$ is then convolved as follows:

$\boldsymbol{x}_{\text {coarse }}=\mathbf{A} \mathbf{L}^{*} \boldsymbol{x}_{\text {fine }}$.

The upper altitude of the convolved profile is chosen at the OMPS-LP grid level, whose corresponding AK altitude range is fully covered by the sonde profile. An alternative approach to the AK convolution assumes a simple vertical average, considering $2.5 \mathrm{~km}$ (i.e $\pm 1.25 \mathrm{~km}$ ) ranges around each grid point (value corresponding to an average vertical resolution of the retrieval scheme below $30 \mathrm{~km}$; refer to Fig. 5). As a consequence, the altitude ranges available for the comparison are different depending on the chosen approach. The altitude at which a cloud is detected and all altitudes below are screened out. Latitude bins are selected in the same manner as in the previous comparisons.

Figure 9 shows averaged collocated profiles in the tropical and northern midlatitude bands with corresponding standard deviations. On the left side of these plots, the number of available collocations at each altitude is reported, which is about 220 and 370 for tropical and northern midlatitude bands, respectively. Overall, 37 ozonesonde stations were considered, corresponding to over 1300 single collocated profiles.

Figure 10 shows the relative differences (Eq. 9) in five latitudinal bands, in panel (a) using the averaging kernel convolution approach and in panel (b) the vertical averaging.
Differences between the two panels of this figure show that the averaging procedure can be critical in the comparison between 15 and $20 \mathrm{~km}$, where the gradient in the ozone profile is usually strong. As shown in Figs. 9 and 10, an excellent agreement is found at northern midlatitudes, with relative differences mostly within $\pm 3 \%$ between 13 and $30 \mathrm{~km}$. Towards northern polar regions, a similar agreement is found with a positive bias of $3 \%$ down to $12 \mathrm{~km}$. At southern midlatitudes, we notice a fairly constant positive difference between 20 and $30 \mathrm{~km}$, with values of $4-6 \%$. A similar positive bias at southern midlatitudes is also visible in Fig. 7. At southern polar latitudes the agreement is slightly worse, with a discrepancy up to $7 \%$ above $13 \mathrm{~km}$. Focusing on the tropical region, a bias between the two data sets is clearly visible, with differences around $2-20 \%$ above $13 \mathrm{~km}$. The positive bias above $17 \mathrm{~km}$ is unexpected considering the good agreement found when comparing it to MLS data in the same region, even though a positive anomaly is also visible in Fig. 8 at about $18-20 \mathrm{~km}$ between 20 and $0^{\circ} \mathrm{S}$.

Looking at panel (b) of Fig. 10, the same patterns are depicted but stronger oscillations below $20 \mathrm{~km}$ are found due to the smaller vertical range over which the sonde profiles are averaged.

With respect to the bias found in the tropical region, the processing of the OMPS-LP 2013 data set is also performed using the same retrieval settings. The analysis of these results and their validation against ozonesondes reveals a much smaller bias in the tropics. Relative differences between IUPOMPS and sonde profiles in the same five latitudinal bands are shown in Fig. 11, following the averaging kernel convolution approach. Since most of the tropical sondes considered over the year 2016 come from the SHADOZ archive, we also take only measurements from the same archive for the 2013 validation: over the whole year, around 200 collocations are available from 10 stations in the tropics and around $1000 \mathrm{col}-$ locations from 30 stations at middle and high latitudes. In 

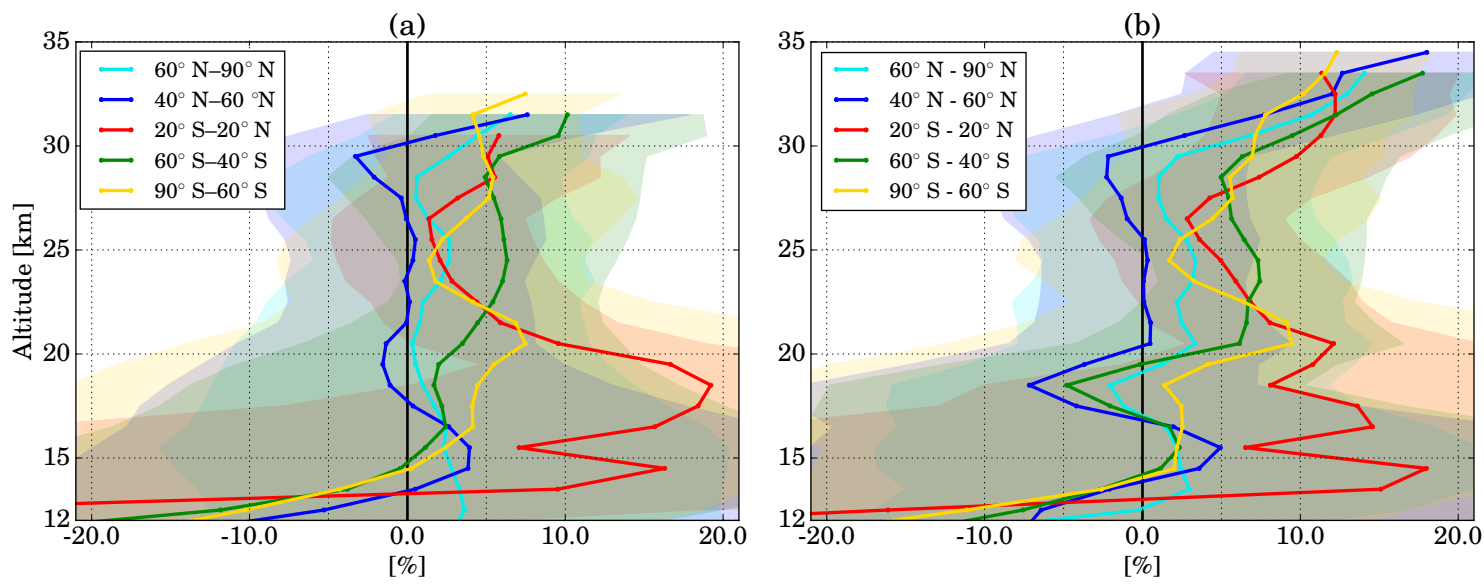

Figure 10. Relative differences between collocated IUP-OMPS profiles and ozonesonde measurements in five latitudinal bands $\left(60-90^{\circ} \mathrm{N}\right.$, $40-60^{\circ} \mathrm{N}, 20^{\circ} \mathrm{S}-20^{\circ} \mathrm{N}, 60-40^{\circ} \mathrm{S}$ and $90-60^{\circ} \mathrm{S}$ ), using (a) averaging kernel convolution and (b) vertical averaging. Corresponding standard deviations are shown as shaded areas.

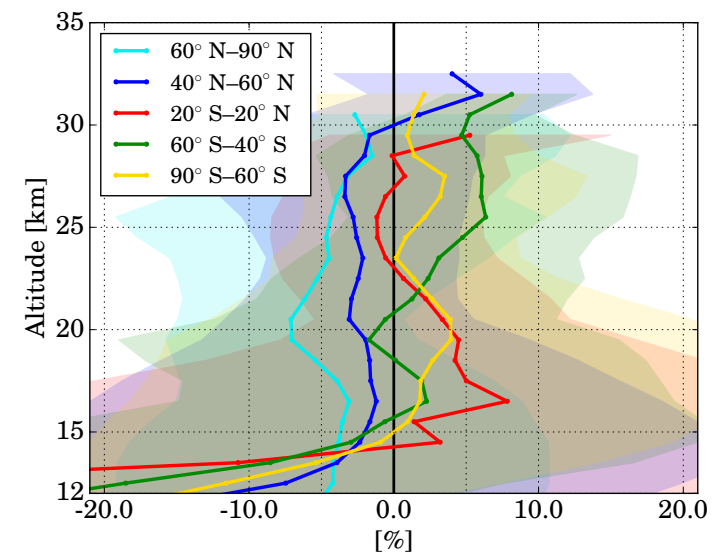

Figure 11. Relative differences between collocated IUP-OMPS profiles and ozonesonde measurements in five latitudinal bands (60$90^{\circ} \mathrm{N}, 40-60^{\circ} \mathrm{N}, 20^{\circ} \mathrm{S}-20^{\circ} \mathrm{N}, 60-40^{\circ} \mathrm{S}$ and $90-60^{\circ} \mathrm{S}$ ) for the 2013 data set, with corresponding standard deviations as shaded areas.

Fig. 11, focusing our attention on the differences in the tropical region, we can see that between 14 and $30 \mathrm{~km}$ the bias is mostly within $5 \%$, although a discrepancy of about $8 \%$ is still evident at about $16 \mathrm{~km}$. Considering all the latitude bands, an agreement within $8 \%$ is seen at all altitudes above $14 \mathrm{~km}$, as found in Fig. 10a. A comparison with MLS shows a very similar pattern to the one observed for the 2016 data set. A possible reason for this difference between the data from 2013 and 2016 is a jump of about $100 \mathrm{~m}$ in the pointing of the instrument that the NASA team detected in September 2014 and that was not corrected in L1 data. The effect of this small jump would be particularly evident at altitudes where ozone profile shows the strongest gradient, that is around $18-22 \mathrm{~km}$ in the tropics, and it is in agreement with the slight shift of the two profiles visible in panel (a) of Fig. 9, even though this is not found in the comparison with MLS. To conclude, we find a general consistency in IUP-OMPS retrieval results, with ozonesonde measurements in all considered latitude bands except for the $12-20 \mathrm{~km}$ altitude range in the tropics, where the agreement with SHADOZ ozonesondes is ambiguous.

\section{Conclusions}

The retrieval algorithm originally developed at the University of Bremen to obtain vertical distributions of ozone from SCIAMACHY limb measurements was tailored and applied to OMPS-LP observations. The $\mathrm{v} 2.5 \mathrm{~L} 1 \mathrm{G}$ data set from the whole of 2016 was processed, analysed and validated, and the results were presented here. Ozone profiles were retrieved between 12 and $60 \mathrm{~km}$, considering only the central slit of the instrument and observations at a solar zenith angle less than $80^{\circ}$. A comparison with NASA v2.5 L2 official product was carried out: we found an overall good agreement with the UV product at all latitude bands, with discrepancies typically within $\pm 5 \%$, except around 45 and $50 \mathrm{~km}$. The comparison with the Vis product above $20 \mathrm{~km}$ showed good consistency in general, even though a discrepancy of $7-12 \%$ was observed above $27 \mathrm{~km}$ at northern midlatitudes and polar regions. We presented the results of the validation against MLS v4.2 ozone profiles and ozonesonde measurements from SHADOZ and WOUDC archives. A good agreement was found with the MLS ozone product: relative differences were generally within $\pm 5 \%$ between 20 and $58 \mathrm{~km}$. On the other hand, we observed a larger discrepancy between IUP-OMPS retrievals and MLS in the tropical UTLS region, most probably related to smaller ozone amounts, larger dynamical variations and the decreasing sensitivity of limb retrievals from both instruments in this region. With regard to the comparison with ozonesondes, we found differences within $\pm 5 \%$ between 13 and $30 \mathrm{~km}$ at northern middle and 
high latitudes, and at southern middle and high latitudes a positive bias about 5-7\% was found for the same range. Focusing on the tropical region, a significant positive bias with SHADOZ measurements was detected, which was unexpected after the good agreement observed with the MLS data. However, the processing and validation of the 2013 data set using the same retrieval settings revealed a much better consistency. The reasons for this behaviour are still under investigation, but are possibly related to a jump in the pointing of the instrument that occurred in 2014. In light of the results presented here, additional work is needed to tune some retrieval settings before processing the whole data set and attempting to merge it with the SCIAMACHY time series. Since the same 1-D retrieval approach has been used for both data sets, we expect this to ease the merging. Unfortunately, only a couple of overlapping months between the two instruments are available, so a third product must be used for the merging. Due to the good agreement found in the comparison of our retrievals with MLS, we are considering the use of the latter instrument as a transfer function to handle calibration issues in the merging procedure.

Data availability. Ancillary information and v2.5 L1G OMPSLP data were downloaded from https://ozoneaq.gsfc.nasa.gov/data/ omps/ (NASA, 2017), where L2 data are also available.

For the validation sections, MLS L2 data were taken from https: //disc.gsfc.nasa.gov/datasets. WOUDC data were downloaded on 5 February 2018 from https://woudc.org/data/explore.php. A list of all contributors is available on the following website: https: //woudc.org/contributors/. SHADOZ data were downloaded on 5 February 2018 from https://tropo.gsfc.nasa.gov/shadoz/Archive. html (NASA, 2018). Our results are available upon request from the University of Bremen.

Author contributions. CA adapted the retrieval algorithm to OMPS-LP observations, processed the data set, performed the validation of the results and wrote the manuscript. AR provided the retrieval algorithm exploited in this study, supervised and guided the retrieval process and reviewed the paper. EM provided retrieved aerosol extinction profiles. K-UE contributed the algorithm for cloud filtering that was adapted to OMPS-LP observations. TvC contributed to the discussion of the regularization matrices for the retrieval scheme and the proper use of averaging kernels to smooth the ozonesonde profiles and reviewed the paper. JPB, who proposed the research and leads the project, analysed the results and contributed to the writing of the manuscript and the scientific outcomes.

Competing interests. The authors declare that they have no conflict of interest. Thomas von Clarmann is the associated editor of AMT but is not involved in the reviewing of this particular paper.

Special issue statement. This article is part of the special issue "Quadrennial Ozone Symposium 2016 - Status and trends of at- mospheric ozone (ACP/AMT inter-journal SI)". It is a result of the Quadrennial Ozone Symposium 2016, Edinburgh, United Kingdom, 4-9 September 2016.

Acknowledgements. This work was partially funded by ESA within the Ozone CCI project and was supported by the University of Bremen and the state of Bremen. We would like to acknowledge NASA OMPS SIPS team (in particular Glen Jaross, Natalya Kramarova, and Pawan K. Bhartia) for the support provided during the data analysis as well as for the concession of the new v2.5 of OMPS-LP L1G data before its official release. Part of the data processing has been done on the German HLRN (High Performance Computer Center North). The GALAHAD Fortran Library was employed in the retrieval scheme.

The article processing charges for this open-access publication were covered by the University of Bremen.

Edited by: Richard Eckman

Reviewed by: two anonymous referees

\section{References}

Aschmann, J., Burrows, J. P., Gebhardt, C., Rozanov, A., Hommel, R., Weber, M., and Thompson, A. M.: On the hiatus in the acceleration of tropical upwelling since the beginning of the 21st century, Atmos. Chem. Phys., 14, 12803-12814, https://doi.org/10.5194/acp-14-12803-2014, 2014.

Bhartia, P., Jaross, G., Larsen, J., and Fleig, A.: Science Team Evaluation of the OMPS Limb Profiler, Tech. rep., 2013.

Bogumil, K., Orphal, J., Burrows, J. P., et al.: Temperature dependent absorption cross sections of $\mathrm{O}_{3}, \mathrm{NO}_{2}$, and other atmospheric trace gases measured with the SCIAMACHY spectrometer, in: Proceedings of the ERS-Envisat-Symposium, Goteborg, Sweden, 2000.

Burrows, J., Hölzle, E., Goede, A., Visser, H., and Fricke, W.: SCIAMACHY - Scanning imaging absorption spectrometer for atmospheric chartography, Acta Astronautica, 35, 445-451, 1995.

Davis, S. M., Rosenlof, K. H., Hassler, B., Hurst, D. F., Read, W. G., Vömel, H., Selkirk, H., Fujiwara, M., and Damadeo, R.: The Stratospheric Water and Ozone Satellite Homogenized (SWOOSH) database: a long-term database for climate studies, Earth Syst. Sci. Data, 8, 461-490, https://doi.org/10.5194/essd8-461-2016, 2016.

DeLand, M., Bhartia, P., Xu, P., Kramarova, N., and Zhu, T.: OMPS Limb Profiler Ozone Product O3: Version 2.5 Data Release Notes, 2017.

Eckert, E., von Clarmann, T., Kiefer, M., Stiller, G. P., Lossow, S., Glatthor, N., Degenstein, D. A., Froidevaux, L., GodinBeekmann, S., Leblanc, T., McDermid, S., Pastel, M., Steinbrecht, W., Swart, D. P. J., Walker, K. A., and Bernath, P. F.: Drift-corrected trends and periodic variations in MIPAS IMK/IAA ozone measurements, Atmos. Chem. Phys., 14, 25712589, https://doi.org/10.5194/acp-14-2571-2014, 2014.

Eichmann, K.-U., Lelli, L., von Savigny, C., Sembhi, H., and Burrows, J. P.: Global cloud top height retrieval using SCIAMACHY 
limb spectra: model studies and first results, Atmos. Meas. Tech., 9, 793-815, https://doi.org/10.5194/amt-9-793-2016, 2016.

Farman, J. C., Gardiner, B. G., and Shanklin, J. D.: Large losses of total ozone in Antarctica reveal seasonal $\mathrm{ClOx} / \mathrm{NOx}$ interaction, Nature, 315, 207-210, 1985.

Flynn, L., Long, C., Wu, X., Evans, R., Beck, C., Petropavlovskikh, I., McConville, G., Yu, W., Zhang, Z., Niu, J., Beach, E., Hao, Y., Pan, C., Sen, B., Novicki, M., Zhou, S., and Seftor, C.: Performance of the ozone mapping and profiler suite (OMPS) products, J. Geophys. Res.-Atmos., 119, 6181-6195, 2014.

Froidevaux, L., Anderson, J., Wang, H.-J., Fuller, R. A., Schwartz, M. J., Santee, M. L., Livesey, N. J., Pumphrey, H. C., Bernath, P. F., Russell III, J. M., and McCormick, M. P.: Global OZone Chemistry And Related trace gas Data records for the Stratosphere (GOZCARDS): methodology and sample results with a focus on $\mathrm{HCl}, \mathrm{H}_{2} \mathrm{O}$, and $\mathrm{O}_{3}$, Atmos. Chem. Phys., 15, 1047110507, https://doi.org/10.5194/acp-15-10471-2015, 2015.

Gebhardt, C., Rozanov, A., Hommel, R., Weber, M., Bovensmann, H., Burrows, J. P., Degenstein, D., Froidevaux, L., and Thompson, A. M.: Stratospheric ozone trends and variability as seen by SCIAMACHY from 2002 to 2012, Atmos. Chem. Phys., 14, 831-846, https://doi.org/10.5194/acp-14-831-2014, 2014.

Gottwald, M. and Bovensmann, H.: SCIAMACHY-Exploring the changing Earth's Atmosphere, Springer Science \& Business Media, 2011.

Hassler, B., Petropavlovskikh, I., Staehelin, J., August, T., Bhartia, P. K., Clerbaux, C., Degenstein, D., Mazière, M. D., Dinelli, B. M., Dudhia, A., Dufour, G., Frith, S. M., Froidevaux, L., GodinBeekmann, S., Granville, J., Harris, N. R. P., Hoppel, K., Hubert, D., Kasai, Y., Kurylo, M. J., Kyrölä, E., Lambert, J.-C., Levelt, P. F., McElroy, C. T., McPeters, R. D., Munro, R., Nakajima, H., Parrish, A., Raspollini, P., Remsberg, E. E., Rosenlof, K. H., Rozanov, A., Sano, T., Sasano, Y., Shiotani, M., Smit, H. G. J., Stiller, G., Tamminen, J., Tarasick, D. W., Urban, J., van der A, R. J., Veefkind, J. P., Vigouroux, C., von Clarmann, T., von Savigny, C., Walker, K. A., Weber, M., Wild, J., and Zawodny, J. M.: Past changes in the vertical distribution of ozone - Part 1: Measurement techniques, uncertainties and availability, Atmos. Meas. Tech., 7, 1395-1427, https://doi.org/10.5194/amt-7-13952014, 2014.

Hess, M., Koepke, P., and Schult, I.: Optical properties of aerosols and clouds: The software package OPAC, Bulletin of the American meteorological society, 79, 831-844, 1998.

Jaross, G., Bhartia, P. K., Chen, G., Kowitt, M., Haken, M., Chen, Z., Xu, P., Warner, J., and Kelly, T.: OMPS Limb Profiler instrument performance assessment, J. Geophys. Res.-Atmos., 119, 4399-4412, 2014.

Jia, J., Rozanov, A., Ladstätter-Weißenmayer, A., and Burrows, J. P.: Global validation of SCIAMACHY limb ozone data (versions 2.9 and 3.0, IUP Bremen) using ozonesonde measurements, Atmos. Meas. Tech., 8, 3369-3383, https://doi.org/10.5194/amt-83369-2015, 2015.

Kahn, D. and Kowitt, M.: Limb Gridded Radiance User Guide, LPL1G-EV-1.0, version 2.0, Tech. rep., 2015.

Kyrölä, E., Laine, M., Sofieva, V., Tamminen, J., Päivärinta, S.M., Tukiainen, S., Zawodny, J., and Thomason, L.: Combined SAGE II-GOMOS ozone profile data set for 1984-2011 and trend analysis of the vertical distribution of ozone, Atmos. Chem.
Phys., 13, 10645-10658, https://doi.org/10.5194/acp-13-106452013, 2013.

Li, F., Stolarski, R. S., and Newman, P. A.: Stratospheric ozone in the post-CFC era, Atmos. Chem. Phys., 9, 2207-2213, https://doi.org/10.5194/acp-9-2207-2009, 2009.

Livesey, N., Read, W., Wagner, P., Froidevaux, L., Lambert, A., Manney, G. L., Millan Valle, L. F., Pumphrey, H. C., Santee, M. L., Schwartz, M. J., Wang, S., Fuller, R. A., Jarnot, R. F., Knosp, B. W., and Martinez, E.: Version 4.2x Level 2 data quality and description, available at: https://mls.jpl.nasa.gov/data/v4-2_ data_quality_document.pdf (last access: 12 April 2018), 2017.

Llewellyn, E. J., Degenstein, D. A., McDade, I. C., Gattinger, R. L., King, R., Buckingham, R., Richardson, E. H ., Murtagh, D. P., Evans, W. F. J., Solheim, B. H., Strong, K., and McConnel, J. C.: Osiris - An Application of Tomography for Absorbed Emissions in Remote Sensing, in: Applications of Photonic Technology 2, 627-632, Springer, 1997.

Molina, M. J. and Rowland, F. S.: Stratospheric sink for chlorofluoromethanes: chlorine atom-catalysed destruction of ozone, Nature, 249, 810-812, 1974.

Moy, L., Bhartia, P. K., Jaross, G., Loughman, R., Kramarova, N., Chen, Z., Taha, G., Chen, G., and Xu, P.: Altitude registration of limb-scattered radiation, Atmos. Meas. Tech., 10, 167-178, https://doi.org/10.5194/amt-10-167-2017, 2017.

NASA: OMPS data, available at: https://ozoneaq.gsfc.nasa.gov/ data/omps/, last access: October 2017.

NASA: SHADOZ data, available at: https://tropo.gsfc.nasa.gov/ shadoz/Archive.html, last access: February 2018.

Nedoluha, G. E., Siskind, D. E., Lambert, A., and Boone, C.: The decrease in mid-stratospheric tropical ozone since 1991, Atmos. Chem. Phys., 15, 4215-4224, https://doi.org/10.5194/acp15-4215-2015, 2015.

Rault, D. F. and Loughman, R. P.: The OMPS Limb Profiler environmental data record algorithm theoretical basis document and expected performance, IEEE T. Geosci. Remote, 51, 2505-2527, 2013.

Rieger, L., Malinina, E., Rozanov, A., Burrows, J. P., Bourassa, A., and Degenstein, D.: A study of the approaches used to retrieve aerosol extinction, as applied to limb observations made by OSIRIS and SCIAMACHY, Atmos. Meas. Tech., submitted, 2017.

Rodgers, C. D.: Inverse methods for atmospheric sounding: theory and practice, vol. 2, World scientific, 2000.

Rozanov, A., Weigel, K., Bovensmann, H., Dhomse, S., Eichmann, K.-U., Kivi, R., Rozanov, V., Vömel, H., Weber, M., and Burrows, J. P.: Retrieval of water vapor vertical distributions in the upper troposphere and the lower stratosphere from SCIAMACHY limb measurements, Atmos. Meas. Tech., 4, 933-954, https://doi.org/10.5194/amt-4-933-2011, 2011.

Rozanov, A. V., Rozanov, V. V., and Burrows, J. P.: Combined differential-integral approach for the radiation field computation in a spherical shell atmosphere: Nonlimb geometry, J. Geophys. Res.-Atmos., 105, 22937-22942, 2000.

Rozanov, V., Rozanov, A., Kokhanovsky, A., and Burrows, J.: Radiative transfer through terrestrial atmosphere and ocean: software package SCIATRAN, J. Quant. Spectrosc. Ra., 133, 13-71, 2014.

Serdyuchenko, A., Gorshelev, V., Weber, M., Chehade, W., and Burrows, J. P.: High spectral resolution ozone absorption cross- 
sections - Part 2: Temperature dependence, Atmos. Meas. Tech., 7, 625-636, https://doi.org/10.5194/amt-7-625-2014, 2014.

Sofieva, V. F., Kyrölä, E., Laine, M., Tamminen, J., Degenstein, D., Bourassa, A., Roth, C., Zawada, D., Weber, M., Rozanov, A., Rahpoe, N., Stiller, G., Laeng, A., von Clarmann, T., Walker, K. A., Sheese, P., Hubert, D., van Roozendael, M., Zehner, C., Damadeo, R., Zawodny, J., Kramarova, N., and Bhartia, P. K.: Merged SAGE II, Ozone_cci and OMPS ozone profile dataset and evaluation of ozone trends in the stratosphere, Atmos. Chem. Phys., 17, 12533-12552, https://doi.org/10.5194/acp-17-125332017, 2017.

Solomon, S., Ivy, D. J., Kinnison, D., Mills, M. J., Neely, R. R., and Schmidt, A.: Emergence of healing in the Antarctic ozone layer, Science, 353, 269-274, 2016.

Steinbrecht, W., Froidevaux, L., Fuller, R., Wang, R., Anderson, J., Roth, C., Bourassa, A., Degenstein, D., Damadeo, R., Zawodny, J., Frith, S., McPeters, R., Bhartia, P., Wild, J., Long, C., Davis, S., Rosenlof, K., Sofieva, V., Walker, K., Rahpoe, N., Rozanov, A., Weber, M., Laeng, A., von Clarmann, T., Stiller, G., Kramarova, N., Godin-Beekmann, S., Leblanc, T., Querel, R., Swart, D., Boyd, I., Hocke, K., Kämpfer, N., Maillard Barras, E., Moreira, L., Nedoluha, G., Vigouroux, C., Blumenstock, T., Schneider, M., García, O., Jones, N., Mahieu, E., Smale, D., Kotkamp, M., Robinson, J., Petropavlovskikh, I., Harris, N., Hassler, B., Hubert, D., and Tummon, F.: An update on ozone profile trends for the period 2000 to 2016, Atmos. Chem. Phys., 17, 1067510690, https://doi.org/10.5194/acp-17-10675-2017, 2017.

Stiller, G. P., Fierli, F., Ploeger, F., Cagnazzo, C., Funke, B., Haenel, F. J., Reddmann, T., Riese, M., and von Clarmann, T.: Shift of subtropical transport barriers explains observed hemispheric asymmetry of decadal trends of age of air, Atmos. Chem. Phys., 17, 11177-11192, https://doi.org/10.5194/acp-17-111772017, 2017.
Thompson, A. M., Witte, J. C., Smit, H. G., Oltmans, S. J., Johnson, B. J., Kirchhoff, V. W., and Schmidlin, F. J.: Southern Hemisphere Additional Ozonesondes (SHADOZ) 1998-2004 tropical ozone climatology: 3. Instrumentation, station-to-station variability, and evaluation with simulated flight profiles, J. Geophys. Res.-Atmos., 112, https://doi.org/10.1029/2005JD007042, 2007.

Tikhonov, A. N.: Solution of incorrectly formulated problems and the regularization method, Soviet Math. Dokl., 4, 1035-1038, 1963.

von Clarmann, T.: Smoothing error pitfalls, Atmos. Meas. Tech., 7, 3023-3034, https://doi.org/10.5194/amt-7-3023-2014, 2014.

Waters, J. W., Froidevaux, L., Harwood, R. S., Jarnot, R. F., Pickett, H. M., Read, W. G., Siegel, P. H., Cofield, R. E., Filipiak, M. J., Flower, D. A., Holden, J. R., Lau, G. K., Livesey, N. J., Manney, G. L., Pumphrey, H. C., Santee, M. L., Wu, D. L., Cuddy, D. T., Lay, R. R., Loo, M. S., Perun, V. S., Schwartz, M. J., Stek, P. C., Thurstans, R. P., Boyles, M. A., Chandra, K. M., Chavez, M. C., Chen, G.-S., Chudasama, B. V., Dodge, R., Fuller, R. A., Girard, M. A., Jiang, J. H., Jiang, Y., Knosp, B. W., LaBelle, R. C., Lam, J. C., Lee , K. A., Miller, D., Oswald, J. E., Patel, N. C., Pukala, D. M., Quintero, O., Scaff, D. M., Van Snyder, W., Tope, M. C., Wagner, P. A., and Walch, M. J.: The earth observing system microwave limb sounder (EOS MLS) on the Aura satellite, IEEE T. Geosci. Remote, 44, 1075-1092, 2006.

Zawada, D. J., Rieger, L. A., Bourassa, A. E., and Degenstein, D. A.: Tomographic retrievals of ozone with the OMPS Limb Profiler: algorithm description and preliminary results, Atmos. Meas. Tech. Discuss., https://doi.org/10.5194/amt-2017-236, in review, 2017. 